\title{
Experimentação multissensorial para ensino de Cinética e Cinemática na perspectiva do aluno deficiente visual: Relato de experiência de oficinas pedagógicas
}

\section{Multisensory experimentation for teaching kinetics and kinematics from the perspective of visually impaired students: Experience report of pedagogical workshops}

\author{
Maura Luise Bruckchem Peixoto (mlbruckchem@gmail.com) \\ Universida de Federal do Rio Grande, Escola de Química e Alimentos - EQA \\ Patrícia Ignácio (patricia.ignacio @ furg.br) \\ Universida de Federal do Rio Gra nde, Instituto de Educação - IE \\ Marcelo Godoi (marcelogodoi@ furg.br) \\ Universida de Federal do Rio Gra nde, Escola de Química e Alimentos - EQA
}

\begin{abstract}
Resumo: Neste artigo são apresentados os resultados obtidos durante a aplicação de oficinas pedagógicas que inseriram tópicos de Cinética Química e Cinemática em aulas de Ciências no nono ano do Ensino Fundamental. A pesquisa foi desenvolvida com um aluno de baixa visão e quatorze videntes, em uma escola na Região Metropolitana de Porto Alegre. As oficinas objetivaram a realização de atividades multissensoriais que possibilitassem melhor motivação, participação e facilitação do processo de aprendizagem do referido aluno com a turma e com os conteúdos trabalhados durante o desenvolvimento das mesmas. Após a análise de resultados, percebeu-se que a adaptação de recursos contribui significativamente para melhor assimilação dos conceitos trabalhados.
\end{abstract}

Palavras-chave: Educação inclusiva; ensino de Ciências; deficiência visual; experimentação multissensorial.

Abstract: Herein, we have reported the results obtained during the application of pedagogical workshops which inserted topics of chemical kinetics and kinematics in science classes in the ninth year of elementary school. The research was developed with a low vision student and fourteen normal visual acuity students in a school in the Metropolitan Region of Porto Alegre. The workshops aimed to develop multisensory activities which resulted in better motivation, participation and facilitation of the learning process of the low vision student and his class colleagues. After the results analysis, it was noticed that the adaptation of resources contributed significantly to better assimilation of the concepts worked.

Keywords: Inclusive education; Science teaching; visual impairment; multisensory experimentation. 


\section{INTRODUÇÃO}

Embora a educação inclusiva seja tema de estudos, debates e discussões já há algum tempo na comunidade escolar, na academia e na sociedade e esteja materializada em leis e documentos - como a Lei de Diretrizes e Bases da Educação Nacional (BRASIL, 1996) e a Declaração de Salamanca de 1994 (BRASIL, 1994) -, observa-se ainda uma lacuna no que se refere a abordagens metodológicas e recursos adaptados para o ensino de Ciências (ARAGÃO, 2012; BERTALLI, 2010; PASSOS, 2013; PIRES, 2010) nos anos finais do Ensino Fundamental, voltados a alunos com deficiência visual. No Brasil, de acordo com o IBGE, há aproximadamente 6 milhões de pessoas que se enquadram na classificação de pessoa combaixa visão e 500 mil pessoas cegas (BRASIL, 2015). Ainda, do total de 971.172 alunos de educação especial matriculados em escolas especializadas e regulares, 76.470 são cegos ou têm baixa visão (BRASIL, 2017).

Em relação ao ensino de deficientes visuais, de acordo com estudo desenvolvido por Costa, Neves e Barone (2006), diversos fatores podem comprometer a integração desses sujeitos em salas de aula regulares. Tais como: falta de recursos didáticos adequados; ausência de experimentação; metodologias visuais de ensino; dentre outras condições que podem se tornar obstáculos durante o processo de aprendizagem. Além disso, em se tratando do estudo das Ciências na Natureza, onde é necessária a compreensão de fenômenos em nível macro e microscópico, metodologias que dependam estritamente de modelos visuais podem significar um grande problema na perspectiva do aluno deficiente visual. Adicionalmente, pensar em recursos didáticos que evitem um ensino baseado apenas na repetição verbal pode favorecer a aprendizagem não somente deste, mas dos alu nos como um todo (SIMÕES, 2018; BARROS; FILHO, 2019; COSTA; VINHOLI; GOBARA, 2019).

Desse modo, em concordância com as questões acima mencionadas, o presente relato de experiência visa apresentar os resultados obtidos durante o desenvolvimento de duas oficinas pedagógicas, realizadas em 2017, que objetivaram - além da adaptação de recursos e metodologias que envolvessem deficientes visuais e videntes em uma mesma atividade -, a experimentação multissensorial, de maneira a dar conta das múltiplas possibilidades de aprendizagem dos alunos deficientes visuais e videntes para o ensino de conceitos ligados à Cinemática e Cinética Química, em uma turma de nono ano do Ensino Fundamental.

Recebido em: 30 /04/ 2020

Aceito em: 19/11/2020 


\section{CONTEXTO E DETALHAMENTO DAS ATIVIDADES}

As atividades foram realizadas em 2017, em uma instituição de ensino básica privada, localizada na Região Metropolitana de Porto Alegre - RS, em uma turma de nono ano do Ensino Fundamental, composta por 15 alunos. Desses, um alunoapresentava baixa visão (denominado neste relato a partir da sigla "ABV", aluno com baixa visão), possuindo cerca de $15 \%$ da mesma.

Assim, para a composição do quadro de atividades, realizaram-se oito horas de observações da turma-alvo da pesquisa em sua rotina e ambiente escolar, analisando-se pontos como: i) relação interpessoal professor-aluno; ii) relação interpessoal aluno-turma; iii) relação do aluno com a disciplina de ciências. Além disso, discutiu-se com professores, alunos e coordenação pedagógica, de maneira a elaborar as oficinas de acordo com o planejamento do professor e o Projeto Político Pedagógico da escola.

As oficinas pedagógicas foram realizadas em dois dias, totalizando quatro períodos (180 minutos), durante as aulas de Ciências. Nelas, foram realizadas atividades que objetivaram o ensino de conteúdos ligados à Cinética Química e à Cinemática, através de recursos multissensoriais adaptados, visando a integração do ABV em sua realização e trabalho conjunto com os demais colegas videntes. Para registro dos dados, foi utilizado um Diário de Campo.

Com as observações em aula, notou-se que o ABV possuía boa relação com os colegas e professores. Entretanto, alegou ter menos afinidade com Ciências, uma vez que os fenômenos estudados lhe pareciam mais abstratos, quando comparada com outras disciplinas. Quanto aos recursos pedagógicos a ele oferecidos, se utilizava de material impresso com fontes de tamanho ampliado (para facilitar a leitura). Seu caderno era adaptado com linhas de demarcação forte, onde escrevia com letras de forma, tendo em vista não ser alfabetizado em Braille.

Sua avaliação era realizada de maneira escrita (com fonte ampliada e questões mais sucintas), por meio de apresentações orais de trabalhos e elaboração de materiais concretos.

A partir dessas informações, o que se tentou promover foi um conjunto de atividades envolvendo recursos adaptados, pensadas de maneira a possibilitar ao ABV sua participação integral, juntamente com os demais alunos videntes, uma vez percebido

Recebido em: 30 /04/ 2020

Aceito em: 19/11/2020 
que, frequentemente, as atividades propostas ao referido aluno acabavam por ser diferentes daquelas executadas pelos demais. Outro intuito das tarefas foi o de proporcionar maior motivação e participação, de maneira que a execução dessas fosse a mais ativa possível. Para isso, utilizou-se de recursos multissensoriais, já que se observou na literatura que, de maneira geral, quando se tratava de metodologias de ensino para deficientes visuais, o tato acabava sendo o sentido explorado majoritariamente. Para essa finalidade, as atividades foram divididas em duas oficinas pedagógicas. Em uma, trabalhou-se conceitos de Cinemática e, na outra, de Cinética Química.

Indo na esteira do pensamento de Nascimento, Costa e Amin (2010), a Oficina 1, voltada ao ensino de Cinemática, explorou os sentidos de audição e tato. Visto que, segundo os autores, a utilização de modelos palpáveis aliados a ferramentas sonoras, para a identificação do material que estiver sendo referenciado, podem se tornar importantes recursos educacionais, principalmente, em relação ao ensino de deficientes visuais. Assim, para a realização das atividades, utilizou-se o dispositivo Lego NXT. Este dispositivo assemelha-se a um carrinho de controle remoto, funcionando a partir de programações pré-estabelecidas, havendo a possibilidade de programá-lo com recursos sonoros, o que facilita sua utilização na perspectiva de um aluno com deficiência visual.

Primeiramente, os alunos foram incentivados a explorar o dispositivo através do tato, de modo a reconhecerem os seus componentes. Em seguida, com a turma dividida em grupos cada qual com cinco componentes, os alunos sentaram-se ao redor de uma pista construída com cartolina (Figura 1), onde foram estudados conceitos como posição, deslocamento e velocidade dos corpos/objetos.

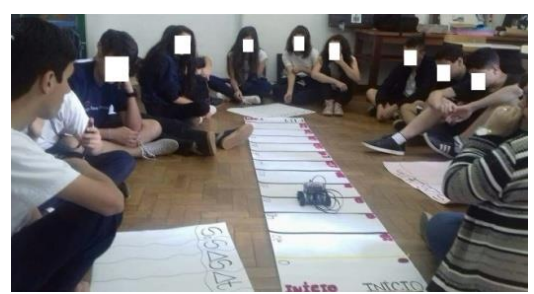

Figura 1. Atividade com Lego NXT para estudo de Cinemática. Fonte: Os autores (2017).

A pista media aproximadamente 2,20 metros e possuía demarcações com fita isolante (de cor preta) a cada 20 centímetros, em relação ao ponto marcado como “inicial”. Os valores correspondentes às posições estavam escritos em tamanho ampliado (também na cor preta), bem como, com numerais feitos em E.V.A texturizado, de forma

Recebido em: 30 /04/ 2020

Aceito em: 19/11/2020 
a facilitar seu reconhecimento através do tato. Um sinal sonoro era emitido pelo dispositivo a cadá demarcação. Aó final, bastava multiplicar a quantidade de sinais emitidos por 20 centímetros, resultando na distância total percorrida.

Além disso, cada grupo recebeu uma tabela elaborada em uma folha de cartolina, na qual registraram dados como posição inicial, posição final, variação de tempo, variação de deslocamento. Por fim, calcularam a velocidade média do movimento do dispositivo, encerrando, assim, as atividades da Oficina 1.

A proposta para a Oficina 2, voltada para o estudo de conceitos da Cinética Química, compreendeu a experimentação multissensorial através do tato, olfato e audição. Para tal, cada aluno recebeu kit e procedimento experimentais individuais. Com a intenção de estimular a exploração dos demais sentidos e vivências que aproximassem a turma do $\mathrm{ABV}$, alguns alunos foram vendados voluntariamente. Os demais alunos foram incumbidos de auxiliar tais colegas durante a realização das atividades. A dinâmica teve como propósito a aproximação dos alunos videntes à realidade $\mathrm{ABV}$, do mesmo modo, mostrar a ele que o fato de necessitar de ajuda e/ou recursos adaptados, não significa que isso seja um inconveniente para o processo de aprendizagem dos demais.

A prática realizada na Oficina 2 consistiu na identificação de fatores que afetam a velocidade das reações químicas, tais como temperatura e superfície de contato. Para tanto, foram utilizados comprimidos efervescentes e água, em diferentes temperaturas, a fim de que os alunos pudessem observar, por meio do tato e da audição, como a dissolução dos comprimidos se deu nas diferentes condições (Figura 2).

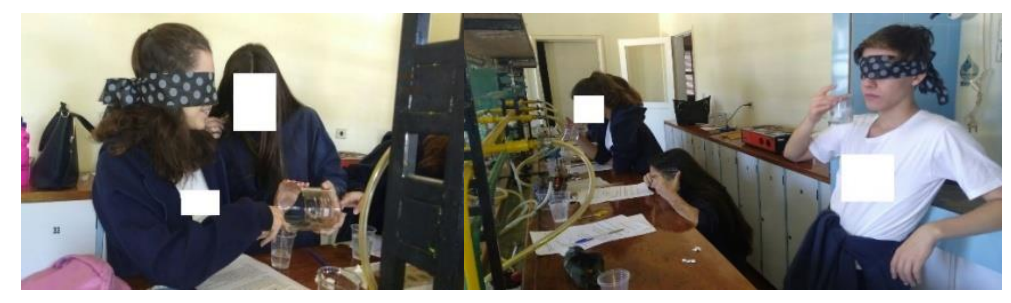

Figura 2. Alunos desenvolvendo as atividades da Oficina 2. Fonte: Os autores (2017).

Nessa atividade, os alunos realizaram relatórios multissensoriais, contendo questões referentes tanto em relação aos materiais utilizados - quantos comprimidos foram usados?; quantos copos de água e quais suas temperaturas?; textura dos comprimidos (se estavam inteiros, macerados ou divididos) -, quanto aos fenômenos observados durante os experimentos - qual comprimido foi dissolvido mais rapidamente Recebido em: $30 / 04 / 2020$ 
e porquê?; como pôde-se perceber o fim da reação?; quais características de dissolução dos comprimidos foram observadas nos diferentes sistemas apresentados?, dentre outras questões.

\section{ANÁLISE E DISCUSSÃO DO RELATO}

A análise dos materiais coletados sinalizou que as oficinas com recursos adaptados para a realização das atividades se mostraram eficientes, uma vez que o ABV obteve resultados satisfatórios durante os experimentos, elaborou hipóteses, sugestões e explicações para os fenômenos observados, desenvolvendo seu pensamento científico, indo ao encontro do que Giordan (1999) destaca em seu trabalho. A exemplo, cita-se o seguinte diálogo, descrito no Diário de Campo:

- Pesquisador: "Sentiu alguma diferença na reação quando usou o comprimido macerado, comparado ao inteiro?"

- ABV: "Ele (o comprimido) se dissolveu muito mais rápido!

- Pesquisador: "Eo que isso significa?"

- ABV: "Que quanto maior o contato com a água, mais rápido ele dissolve”.

Os recursos sonoros atrelados aos recursos táteis também se mostraram importantes aliados para o bom desenvolvimento do $\mathrm{ABV}$ durante as atividades propostas na Oficina 1, ao passo que auxiliam o deficiente visual a ter uma melhor concepção referencial daquilo que está trabalhando, em concordância com o trabalho de Nascimento, Costa e Amin (2010). Como pode-se observar através da seguinte afirmação do ABV: "Ouvi quatro apitos do carrinho, seu deslocamento foi de 80 centímetros".

De maneira geral, o ABV mostrou-se bastante motivado para executar todas as atividades propostas nas duas oficinas, além de apresentar um comportamento bastante autônomo durante a realização de ambas as atividades. O que foi expresso através da afirmação a seguir: "Gostei muito de todas as atividades, porque consegui fazer todase entender o que estava se passando. Queria que tivessem atividades assim em todas as matérias". Com relação aos demais alunos, os mesmos foram bastante participativos e demonstraram grande interesse e satisfação pela maneira como as atividades foram conduzidas.

Recebido em: 30 /04/ 2020 
Outro ponto a ser levado em consideração, foi a dinâmica de vendar alguns alunos durante a Oficina 2. Esses mostraram-se totalmente dependentes dos demais colegas para realizarem suas atividades. Isso reforça a necessidade de se promover atividades que integrem os alunos e mostrem as dificuldades e necessidades dos colegas, de forma a trazer a reflexão acerca do coletivo, do trabalho em conjunto e da solidariedade também em sala de aula, mostrando a importância de se colocar no lugar do outro.

Assim sendo, o que se pode perceber é que as atividades multissensoriais propostas durante o desenvolvimento das oficinas promoveram a motivação, participação, execução e construção de conhecimento de todos os alunos, tendo em vista a obtenção de bons resultados acerca dos critérios estabelecidos.

\section{CONSIDERAÇÕES FINAIS}

Estudos como os de França (2013) e, Bampi, Guilhem e Alves (2010) apontam a ideia de que a deficiência não deve ser entendida como um problema individual, mas como uma questão da vida em sociedade. A principal intervenção deve ser realizada na sociedade para que a participação dos sujeitos com deficiência seja facilitada. Logo, não basta apenas inseri-los no espaço físico da escola, mas sim, trazer metodologias e recursos que possibilitem explorar todas as suas potencialidades. Esse é um papel fundamental não somente dos professores, mas, de toda a comunidade escolar.

Comumente a adoção de recursos táteis acaba se mostrando uma alternativa para o ensino de deficientes visuais. No entanto, é preciso que se (re)pense metodologias capazes de explorar os demais sentidos remanescentes desses sujeitos, de modo a potencializar suas capacidades. Uma das formas possíveis é aliar seus sentidos à experimentação, trabalhando de forma multissensorial, o que pode proporcionar ao aluno deficiente visual uma experiência mais próxima do fenômeno que estiver ocorrendo durante a experimentação, permitindo que o mesmo expanda não somente seus sentidos, mas também seus conhecimentos a respeito do que está sendo estudado.

Os resultados das oficinas pedagógicas apontam para a possibilidade de envolvimento de deficientes visuais em atividades experimentais, em conjunto com os demais alunos, tendo em vista a adaptação de recursos e metodologias que contemplem todos os sujeitos envolvidos nas atividades. Além disso, percebeu-se que os alunos, ao final das atividades, puderam atingir uma das finalidades da oficina pedagógica proposta Recebido em: $30 / 04 / 2020$ 
por Paviani e Fontana (2009): a possibilidade da articulação de conceitos, pressupostos e noçốes com ações concretas, vivenciadas pelo participante.

Cabe ressaltar que uma educação para todos implica não somente na imersão dos alunos com necessidades especiais na sala de aula, mas sim, em um repensar da prática pedagógica de forma a se abrir um leque de possibilidades que façam esses sujeitos sentirem-se partes integrantes da comunidade escolar e da sociedade.

\section{Agradecimentos}

Agradecemos ao Conselho Nacional de Desenvolvimento Científico e Tecnológico-CNPq (428494/2018-8) pelo apoio financeiro, à Coordenação de Aperfeiçoamento de Pessoal de Nível Superior (CAPES) pela bolsa de pós-graduação de M. L. B. P.

\section{REFERENCIAS}

ARAGÃO, Amanda Silva. Ensino de Química para alunos cegos: Desafios no Ensino Médio. 2012. 122 f. Dissertação (Mestrado) - Curso de Pós Graduação em Educação Especial, Centro de Educação e Ciências Humanas, Universidade Federal de São Carlos, São Carlos, 2012.

BAMPI, Luciana Neves da Silba; GUILHEM, Dirce; ALVES, Elioenai Dornelles. Modelo Social: uma nova abordagem para o tema deficiência. Revista Latinoamericana de Enfermagem, S.1, v. 4, n. 18, p.01-09, jul-ago. 2010. Bimestral.

BARROS, Ana Patrícia Martins; FILHO, Francisco Ferreira Dantas. Avaliação de materiais didáticos: uma proposta de ensino do conteúdo geometria molecular para alunos com deficiência visual. Revista Insignare Scientia. S.1, v. 2, n. 4, p. 56-75, mai-ago. 2019.

BERTALLI, Jucilene Gordin. Ensino de geometria molecular, para alunos com e sem deficiência visual, por meio de modelo atômico alternativo. 2010. 70 f. Dissertação (Mestrado) - Curso de Mestrado em Ensino de Ciências, Centro de Ciências Exatas e Tecnologia, Fundação Universidade Federal de Mato Grosso do Sul, Campo Grande, 2010. Cap. 4.

Recebido em: $30 / 04 / 2020$

Aceito em: 19/11/2020 
Edição Especial: XVI Encontro sobre Investigação na Escola - EIE

ISSN: 2595-4520 Vol. 4, n. 2. 2021

BRASIL. Declaração de Salamanca: Sobre Princípios, Políticas e Práticas na Área

das Necessidades Educativas Especiais. Brasília: UNESCO, 1994. Disponível em: <http://unesdoc.unesco.org/images/0013/001393/139394por.pdf>. Acesso em: 28 jun. 2017.

Ministério da Educação. Lei n. 9,394, de 20 de dezembro de 1996. Lei de

Diretrizes e Bases da Educação Nacional. Disponível em: <http://portal.mec.gov.br/seesp/arquivos/pdf/lei9394_ldbn1.pdf>. Acesso em 30 jun. 2017.

Brasil. Portal Brasil (Org.). Braile aumenta inclusão de cegos na

sociedade. 2015. Disponível em: <http://www.brasil.gov.br/cidadania-ejustica/2015/01/braile-aumenta-inclusao-de-cegos-na-sociedade>. Acesso em: 30 jun. 2017.

Brasil. Portal Brasil (Org.). Grafia Química Braille para uso no Brasil é Publicada pelo MEC. 2017. Disponível em: < http://portal.mec.gov.br/ultimasnoticias/202-264937351/55981-grafia-quimica-braille-para-u so-no-brasil-e-publicadapelo-mec>. Acesso em 06 fev. 2019.

COSTA, Luciano Gonsalves; NEVES, Marcos Cesar Danhone; BARONE, Dante Augusto Couto. $\mathrm{O}$ ensino de Física para deficientes visuais a partir de uma perspectiva fenomenológica. Ciência e Educação, S.1, v. 12, n. 2, p.143-153, 2006.

COSTA, Alessandra Françoso da Silva; VINHOLI, Airton José Júnior; GOBARA, Shirley Tedesco. Ensino de Biologia celular por meio de modelos concretos: um estudo de caso no contexto da deficiência visual. Revista Electrónica de Investigación en Educación en Ciencias, Buenos Aires, v. 14, n. 1, p. 50-62, 2019.

FRANÇA, Tiago Henrique. Modelo Social da Deficiência: uma ferramenta sociológica para emancipação social. Lutas Sociais, São Paulo, v. 17, n. 31, p.59-73, jul-dez. 2013. Semestral.

GIORDAN, Marcelo. O papel da experimentação no ensino de ciências. Química Nova na Escola, n. 10, p. 43-49, nov., 1999.

NASCIMENTO, Cristiane da Cunha; COSTA, Silvânio Silvério Lopes da; AMIN, Lucia Helena Luiza Vieira. Repensando o ensino de Química: Uma proposta para deficientes

Recebido em: $30 / 04 / 2020$

Aceito em: $19 / 11 / 2020$ 
Edição Especial: XVI Encontro sobre Investigação na Escola - EIE

ISSN: 2595- 4520 Vol. 4, n. 2. 2021

visuais. In: Colóquio Internacional Educação e Contemporaneidade, 4., 2010, Laranjeiras. Anais... .Laranjeiras. Educon, 2010. p. 1 - 10.

PASSOS, Kamila dos. Entre o material e o abstrato: Manipular o imaginário estudantil para aprendizagens de Química Orgânica. 2013. 66 f. TCC (Graduação) Curso de Licenciatura em Química, Instituto de Química, Universidade Federal do Rio Grande do Sul, Porto Alegre, 2013.

PAVIANI, Neires Maria Soldatelli; FONTANA, Niura Maria. Oficinas Pedagógicas: relato de uma experiência. Conjectura, S.1, p.77-88, mai-ago, 2009.

PIRES, Rejane Ferreira Machado. Proposta de guia para apoiar a prática pedagógica de professores de Química em sala de aula inclusiva com alunos que apresentam deficiência visual. 2010. 158 f. Dissertação (Mestrado) - Curso de Programa de Pósgraduação em Ensino de Ciências, Universidade de Brasília, Brasília, 2010.

SIMÕES, Guilherme Soares. "Me ajuda a entender": Website como ferramenta de apoio para professores no ensino de Química a estudantes com deficiência visual. 2018.142 f. Dissertação (Mestrado) - Mestrado Profissional em Educação e Docência, Universidade Federal de Minas Gerais, Belo Horizonte, 2018.

Recebido em: $30 / 04 / 2020$

Aceito em: 19/11/2020 